\title{
LEONES DE PIEDRA ROMANOS DE LAS CABEZAS DE SAN JUAN (SEVILLA). A PROPÓSITO DE UN NUEVO EJEMPLAR IDENTIFICADO ${ }^{1}$
}

\author{
ROMAN STONE LIONS LAS CABEZAS DE SAN JUAN (SEVILLA). \\ APROPOS OF A NEW SPECIMEN IDENTIFIED \\ por
}

JOSÉ BELTRÁN FORTES

RESUMEN Se estudian esculturas romanas de leones de piedra de época republicana procedentes de Las Cabezas de San Juan y de Lebrija (Sevilla), a propósito de la identificación de un nuevo ejemplar conservado en el Museo Arqueológico de Osuna y en el marco de la problemática general de este tipo estatuario en el sur hispano.

\begin{abstract}
We study some Roman Funerary Sculptures in form of lion, that proceed from Las Cabezas de San Juan and Lebrija (prov. of Seville); specifically a piece of the Archaeological Museum of Osuna. And also the problem of this type sculpture in the southern Spain.
\end{abstract}

Palabras claves Escultura funeraria romana. Baetica. Conobaria.

Key words Roman Funerary Sculptur. Baetica. Conobaria.

Hallanse aquí algunos leones de piedra grandes, y otros pequeños... (Caro 1634: 133 vto.)

Que la actual localidad de Las Cabezas de San Juan (Sevilla) era en época romana un lugar en que debieron ser especialmente abundantes las representaciones escultóricas de leones lo constata de forma fehaciente la explícita indicación que en los comienzos del siglo XVII hace el anticuario Rodrigo Caro en su obra Antigüedades y Principado de la Ilustrissima Ciudad de Sevilla y Chorographia de su Convento Iuridico,

1. Este trabajo corresponde a los trabajos realizados en el marco del Grupo de Investigación HUM 402 (Plan Andaluz de Investigación) y del Proyecto PB98-1136 (Ministerio de Ciencia y Tecnología). 
o Antigua Chancilleria. El erudito andaluz, que debía conocer bien aquellos territorios pues era originario de la cercana localidad de Utrera, justificaba la-debemos pensar-especial abundancia de representaciones leoninas en el sitio cabeceño con la siguiente reflexión:

\begin{abstract}
"Hallanse aquí algunos leones de piedra grandes, y otros pequeños; y la razon es, porque los peregrinos que yvan al templo de Hercules a Cadiz, le consagravan leones, que era la insignia, de cuyas pieles, el viviendo, andava vestido, por aver vencido el leon Nemeo, y tambien, porque aviendo venido el Rey Teron de la Celtiberia, con una grande armada, a robar las riquezas del gran templo de Hercules Gaditano, y aviendo salido contra el las galeras de Cadiz, en el mayor conflicto de la batalla, parecieron leones en las proas de las galeras, y navios de Cadiz: los quales, echando fuego por la boca, abrasaron toda la armada sacrilega del Rey Teron; y por tan insigne maravilla, le consagravan sus devotos tales efigies de leon; assi lo dize Macrobio. Este milagro, si fue verdadero milagro (de que yo dudo mucho, porque Hercules fue un hombre mortal, no digno de adoracion) pudo ser lo permitiesse Dios, por enseñar a los hombres el respeto que deven guardar a la religion, y a los templos, pues aun a los violadores de los falsos dioses castiga assi severamente, como tambien premiò la virtud de la otra virgen vestal, acreditando su castidad con sacar del Tiber agua en un harnero: y de la otra, que con una cinta truxo a tierra un navio, que mucha gente no podia mover. Assi que, por el tal milagro los peregrinos, que de todo el mundo venian a Cadiz, por memoria de su devocion, dedicavan estos leones a su Hercules. Y por esta misma causa se ven en muchas medallas de Cadiz rayos en el reverso dellas." (Caro 1634: 133 vto).
\end{abstract}

En la segunda mitad del siglo XVIII tenemos un nuevo testimonio sobre la presencia de esculturas de leones de piedra en Las Cabezas de San Juan -quizás todavía algunos de los que viera Rodrigo Caro-, así como de otros en el entorno, según manifiesta el eminente prohombre en la Sevilla ilustrada Francisco de Bruna y Ahumada (sobre éste, vid. Romero Murube 1965). Como es sabido, Bruna incorporó a su colección arqueológica y epigráfica que reunía en los Reales Alcázares de Sevilla una interesante escultura cabeceña, aparecida al construir la iglesia parroquial en 1762, que constituye seguramente un pie de mesa decorado con la estatua de Atlas, con un epígrafe dedicatorio al emperador Claudio ${ }^{2}$, y sobre ella llevó a cabo un estudio que fue publicado en el primer volumen de las Memorias Literarias de la Real Academia Sevillana de Buenas Letras, editado en 1773. En ese trabajo, aceptando la explicación recogida en el texto del utrerano, indica sobre la localidad de Las Cabezas:

"En la Plaza existen dos grandes Leones de piedra, de los que sacrificaban por el camino à Hercules los Peregrinos à su famoso templo, semejantes à otros, que se ven à las puertas del Cortijo de Alocaz, y otros, que se descubrieron poco tiempo ha, cavando unas viñas de Paradas, de los quales se ven muchos por toda la ruta del Arrecife." 3 (Bruna 1773: 309).

Por último, hemos de significar el ejemplar descabezado que en 1918 fue donado por el Ayuntamiento de Las Cabezas al Museo Arqueológico Provincial de Sevilla y que hoy se expone en la Sala XI de este

2. La pieza se conserva en el Museo Arqueológico Provincial de Sevilla. Sobre la escultura, Baena (1995). El epígrafe es recogido en CIL II, 1302; CILA 2, 993.

3. Vuelve a indicar Bruna en una obra posterior inédita, cuya copia se conserva en la Biblioteca de la Real Academia de la Historia (cuyo conocimiento debo a J. Salas Álvarez), que: “...en todo aquel camino del arrecife a los Puertos se encuentran monumentos de antigüedad como Leones de Piedra que sacrificaban a Hércules los peregrinos que iban a su famoso templo de Cádiz, de los que hay dos situados a la puerta del Cortijo de Alocaz" (Bruna 1790). Frente a la indicación tradicional, consagrada precisamente por Caro (1634: 133), que fijaba en Las Cabezas de San Juan la Vgia del Itinerario de Antonino, es segura la localización de esta ciudad romana en las tierras de ese "cortijo de Alocaz"; cfr. ahora Beltrán Fortes 1999. El Arrecife era la denominación de la via Augusta; cfr. sobre los diversos caminos existentes durante el siglo XVIII en la zona, Sillières (1976). 
museo $^{4}\left(\mathrm{n}^{\circ}\right.$ inv. 647) (fig. 1). Se trata de una escultura casi completa, aunque tiene significativas pérdidas de la parte delantera de la cabeza y de la pata delantera derecha; lo conservado mide $0,61 \mathrm{~m}$ de altura, 0,34 de anchura y $0,84 \mathrm{~m}$ de longitud máximas, estando elaborado en caliza blanco-grisáceo, seguramente local ${ }^{5}$. Como es la tónica más habitual en estas representaciones de leones hispanorromanos el ejemplar cabeceño se eleva sobre los cuartos traseros mientras apoya las patas delanteras y, como sugiere Pérez López (1999: $80 \mathrm{~s} ., \mathrm{n}^{\circ} 24$, con bibliografía anterior), pudo tener o no la cabeza de un animal bajo su garra derecha. Elemento significativo es la disposición de la melena, mediante una especie de tres anillos concéntricos en los que los mechones se representan de forma esquemática, en un modelo que según la autora citada debe de corresponder a los ejemplares hispanorromanos más antiguos de época republicana, datados posiblemente en la segunda mitad del siglo II a.C. (Pérez López 1999: 20), habiendo sido incluido también con anterioridad por Chapa Brunet (1985: 106) entre los del grupo reciente, de los siglos III a.C. hasta I a.C.

Como se concluye en esas dos importantes obras citadas en las que se estudian-desde diversas perspectivas y planteamientos más o menos amplios- esta serie de estatuaria zoomorfa y frente a las consideraciones del erudito Rodrigo Caro de considerarlos como exvotos en relación con el culto hercúleo, el carácter de estas esculturas de leones es evidentemente funerario y enlazaba en los territorios hispanos con una doble tradición, una que venía del mundo ibérico -más o menos documentada en los territorios surpeninsularesy otra del mundo itálico -en relación con las nuevas presencias que la conquista romana aparejó.

Según afirmara el profesor Blanco Freijeiro (1981: 128):

"Las estatuas de leones como guardianes de tumbas son una típica manifestación de la escultura ibérica desde por lo menos el siglo VI a.C. El mismo fenómeno se observa en Italia, donde sus orígenes se perdían en el pasado legendario: "Dicen algunos también que el león de piedra que estaba en la parte principal del Foro, cerca de los Rostra, fue colocado sobre el cadáver de Fáustulo por quienes lo enterraron en el sitio donde había caído" (Dion. Halic., Ant. Rom., I, 87, 2). Bajo el influjo romano el león ibérico adquiere una nueva fisonomía: se torna más realista, pues no en vano el pueblo se ha familiarizado con él merced a las venationes del anfiteatro, y sujeta bajo una de sus patas una cabeza de carnero u otra presa semejante” .

La ausencia de esculturas funerarias de leones en el ámbito turdetano del Bajo Guadalquivir (que recogen autores como Chapa Brunet 1985: 138ss., o Pérez López 1999: 22) parece apuntar a que los abundantes testimonios documentados en este ámbito geográfico deben conectarse con la presencia romana en estos territorios. Sin embargo, no debe olvidarse la función que tendrían en ese proceso las perduraciones prerromanas, que pudieron influir en las caracterizaciones de grupos regionales (Beltrán Fortes 1997: 119). En ese mismo sentido ha apuntado Lacalle Rodríguez (1998: 167):

"Los leones de época reciente se han relacionado con la llegada de Roma a la Península Ibérica... No obstante, las escasas áreas ocupadas por este tipo de estatuaria, coincidentes con el foco antiguo de leones del Alto Guadalquivir y su área vecina, el Bajo Guadalquivir, pueden hacer pensar que el sustrato indígena que levantaba estos monumentos antes de la llegada de las legiones romanas pueda jugar algún papel en la nueva manifestación artística" .

Como se concluye de la obra ya citada de Pérez López (1999: 17, mapa) existe una clara diferencia formal entre los leones recuperados en el Medio y Alto Guadalquivir-donde, por ejemplo, predomina el gusto por la colocación de cabezas humanas bajo la garra del felino- y en el Bajo Guadalquivir -sólo

4. Agradecemos al Director del Museo, Dr. Fernando Fernández, el permiso para la realización de las fotografías conservadas en esta institución.

5. En el territorio estricto que rodea a la localidad, en un paisaje de terrazas aluviales, no existen afloramientos pétreos, pero sí ya en las cercanos afloramientos montañosos del sureste del término municipal y norte de la provincia de Cádiz (sierra de Espera). 
documentándose cabezas de animales-, aunque para estos últimos la dispersión de casos realmente se concentra en ciudades situadas al este del Guadalquivir, desde Gades y otras localidades del norte de la actual provincia gaditana (Hasta Regia, Carissa Aurelia, Cappa, etc.) hasta ciudades de la actual provincia sevillana como Nabrissa, El Coronil, Utrera o Vrso, siendo éste el punto más extremo que marca el límite hacia el este de este sector que parece responder de forma más clara a una influencia itálica. Bajo este planteamiento debemos incluir, pues, el citado ejemplar de león de Las Cabezas -y los otros ejemplares que repasaremos a continuación-entre la serie de leones funerarios de época romano republicana y altoimperial, ya que en algún caso es posible su datación segura en época augústea, como ocurre con un león de Salaria (cortijo de Doña Aldonza, Úbeda, Jaén), que hemos relacionado con su monumento arquitectónico turriforme coronado con edícula y estatuas funerarias de unos Stlaccii (Beltrán Fortes y Baena del Alcázar 1996), o con los leones de Augusta Emerita (Pérez López 1999: 130ss., $\mathrm{n}^{\text {os }}$ 51-53, algunos ya elaborados en mármol), cuyo momento post quem lo indica la misma fundación de la colonia, para la que debemos seguir aceptando la teoría tradicional. Sin embargo, por sus características formales el ejemplar citado de Las Cabezas de San Juan podría ser considerado como perteneciente a la serie romana más antigua, encuadrable dentro del siglo II a.C.

A este ejemplar conocido desde antiguo podemos sumar ahora otras piezas aparecidas en Las Cabezas de San Juan que representan esculturas zoomorfas similares, de época romana, elaboradas en areniscas locales y de finalidad sepulcral.

En primer lugar, mencionaré una pieza casi completa que, aunque aparecida hace ya algunos decenios en la misma localidad de Las Cabezas -en donde se conserva-, ha sido dada a conocer en fecha reciente por López García (1999). Está elaborada en una arenisca local de color blanco amarillento y mide $0,71 \mathrm{~m}$ de altura, $0,40 \mathrm{~m}$ de anchura y $1,15 \mathrm{~m}$ de longitud máximas (fig. 2). Sólo presenta pérdidas significativas en los cuartos traseros (sobre todo en su parte izquierda), en las pezuñas delanteras y en el frente de la cara, de la que se conserva un fragmento aparte, pero que casa perfectamente, y en el que se advierten la boca abierta con los colmillos y los ojos almendrados (fig. 3). El animal se encuentra en este caso totalmente echado -contra lo que es la norma más habitual de levantar los cuartos traseros o estar completamente alzado sobre las patas- y pasa la cola por debajo de la pata trasera derecha, enrollándola en esa parte del lomo. Como elemento diferenciador frente a las series más frecuentes de leones hispanorromanos podemos resaltar tanto el que no doble la cabeza hacia ninguno de los lados y la correspondiente ausencia de la cabeza del animal bajo una de las zarpas, como el tratamiento de la melena, que sólo queda delimitada por su realzamiento con respecto al cuerpo y al rostro y por un pequeño piqueteado de la superficie. Son peculiaridades formales que -en el estado actual de la investigación y dentro de hipótesis basadas de forma exclusiva en criterios estilísticos-llevan asimismo a proponer una fecha temprana para su elaboración en el siglo II a.C., aunque resaltando esas características excepcionales dentro de la serie de leones de este ámbito territorial de la Hispania Vlterior.

Dentro de la serie ciertamente escasa de paralelos en el sur peninsular hispano podemos mencionar un ejemplar que procede de la vecina localidad de Lebrija, por lo que podemos apuntar a producciones de un mismo taller o, a lo sumo, de talleres que seguían normas similares. Se trata de una escultura leonina que se descubrió reutilizada como elemento constructivo en una casa de Lebrija hacia los años setenta del siglo XX y que se encuentra ahora en una colección particular en la lebrijana hacienda de Micones (Pérez López 1999: 78s., nº 23) (fig. 4), por lo que debe corresponder, pues, a alguna de las necrópolis de la ciudad romana de Nabrissa (sobre ésta Tomassetti Guerra 1997). Formalmente presenta bastantes concomitancias con la pieza cabeceña, como el tipo de arenisca blanco amarillenta, la posición totalmente echada del animal, el que no se coloque una cabeza de carnero o de otro animal bajo la zarpa, la ausencia del tratamiento de los mechones de la melena, estando el rostro simplemente diferenciado de la melena por el abombamiento de ésta, o el predominio de la disposición frontal, aunque con "...suave giro de la cabeza que sigue el modelo de los tiempos romanos”, según Pérez López (1999: 78), para quien todo ello es explicable por su finalidad 
como tapadera de cista, a lo que asimismo apuntan sus pequeñas dimensiones $-0,19 \mathrm{~m}$ de altura por $0,34 \mathrm{~m}$ de longitud-. Aceptando esa función, que explicaría por ejemplo el diverso tratamiento del rostro, más esquematizado en este caso que en el ejemplar cabeceño anteriormente tratado, parece lógico que se inscribe en una forma y estilo de representación escultórica similares, propias de este ámbito territorial y que -para la pieza lebrijana-la hace diferente de otras tapaderas de cistas romano republicanas que disponen la figura de un león como motivo escultórico, como ocurre no sólo con tapaderas de cistas del Alto Guadalquivir (Pérez López 1999: 122s., $\mathrm{n}^{\text {os }}$ 46-47, de Castulo, 128s., nº 50, de Villarrodrigo) sino en ejemplares de la zona, como en una pieza de Carissa Aurelia (Espera-Bornos, Cádiz), donde existe un tratamiento más naturalístico de la melena y se dispone la cabeza de un carnero entre las zarpas (Pérez López 1999: 50s., nº 9).

Este hecho citado, así como la diversidad formal y estilística constatada en representaciones leoninas de Las Cabezas de San Juan y de Lebrija, hace que no podamos esgrimir criterios territoriales para la dispersión de este tipo peculiar al que nos referimos, por lo que quizás se justifique por una diversidad cronológica o -en cualquier caso- por la coetaneidad del uso de ejemplares que respondían a tradiciones o modelos diversos. Así, en efecto, de la misma Nabrissa se conoce desde hace tiempo la existencia de dos esculturas de leones romanos que se integran dentro de las series más frecuentes y en relación con características que son consideradas más vinculadas al mundo romano (Chapa Brunet 1985: 116, foto 10; Pérez López 1999: 74ss., $\mathrm{n}^{\text {os }} 21$ y 22). Se trata de leones elevados sobre los cuartos traseros, con la cabeza de carnero bajo una de las zarpas -aunque en uno falta por rotura-y melena de tipo naturalístico, que hace que debamos datarlos en momentos finales de la época republicana o época julio-claudia (fig. 5).

No nos vamos a detener en esta ocasión en el análisis de dos fragmentos de sendos leones de piedra arenisca que se conservan también en Las Cabezas de San Juan ${ }^{6}$, ya que lo fragmentario de lo conservado (ambos correspondientes a la parte posterior del cuerpo del animal) impide conocer si corresponden a uno u otro grupo, pero en todo caso demuestran esa tradicional abundancia de leones cabeceños de época romana a la que se referían los autores antiguos.

Finalizaré este breve recorrido de los leones de piedra de este sector meridional hispano con la recuperación para el acervo cabeceño de otra escultura de león, especialmente "viajera", de la que se desconocía en la actualidad esta procedencia. La escultura se conservaba en Las Cabezas de San Juan en condiciones que nos son desconocidas -el alto grado de erosión de la piedra puede hacer pensar incluso que correspondiera a una de aquellas piezas que en el siglo XVIII se situaban en la plaza de la localidad y que citaba F. de Bruna-y a fines del siglo XIX debió ser llevada a la cercana población de Los Molares, en cuyo castillo se colocó formando pareja con otro fragmento escultórico de león. Actualmente, por las circunstancias que expondremos a continuación, se exponen en el Museo Arqueológico Municipal de Osuna como procedentes de Los Molares ${ }^{7}$. Sin embargo, de la primera de las piezas citadas sí podemos aseverar la procedencia cabeceña, según se manifiesta en el Catálogo Monumental de España. Provincia de Sevilla, que elaboró entre 1907 y 1909 Adolfo Fernández Casanova, aunque quedó inédito ${ }^{8}$. Adolfo Fernández Casanova (1843-1915) fue

6. Uno se conserva en una colección particular y otro acaba de ser recientemente incorporado a la colección arqueológica municipal; cfr. Beltrán Fortes (e.p.). La recuperación del segundo de ellos -donado a la citada colección municipal- se debe a los desvelos de D. Antonio Jiménez y al apoyo del concejal de Cultura D. Francisco López.

7. Ambas piezas se exponen en la Sala II del Museo. Nuestro agradecimiento a su Director por el permiso para el estudio. La segunda de las citadas, bastante deteriorada y elaborada en arenisca blanco-grisácea, corresponde a la parte delantera del animal, incluyendo la cabeza, que está ligeramente girada hacia su derecha y decorada con una amplia y naturalística melena; mide los conservado $0,74 \mathrm{~m}$ de altura, $0,38 \mathrm{~m}$ de anchura y $0,62 \mathrm{~m}$ de longitud y se representaría originalmente alzado sobre sus patas. No debemos pensar que proceda de Las Cabezas de San Juan, ya que no se ha indicado expresamente como en el caso de su pieza compañera.

8. En la actualidad se conserva como depósito ministerial en el Instituto de Historia del Arte del CSIC de Madrid, donde lo hemos consultado y reproducido su fotografía gracias al permiso correspondiente del Dr. Wifredo Rincón. Copia del Catálogo se encuentra en el Ateneo de Sevilla bajo el título "Guía de los Monumentos históricos y artísticos de la provincia de Sevilla, con exclusión de la capital”, según Jiménez (1999: 31). 
un arquitecto vallisoletano que se encargó desde 1881 de los trabajos de restauración de la Catedral Hispalense, aunque el derrumbamiento de parte del edificio en 1888 y las críticas generadas hicieron que dimitiera al año siguiente y se trasladara a Madrid. Sin embargo, en los primeros años del siglo XX realizó el Catálogo Monumental de la provincia de Sevilla, aunque el contenido arqueológico de la obra no es muy alto como fruto de la propia formación del autor-si la comparamos, por ejemplo, con el interés prestado a los aspectos artísticos y a diferencia de otros Catálogos como los dedicados a Cádiz, Badajoz o Jaén-. Así, sin ningún tipo de estudio o comentario más completo recoge Fernández Casanova bajo el apartado de Las Cabezas de San Juan la referencia de esta escultura leonina, que dice que se conservaba entonces en el castillo utrerano de Los Molares -perteneciente todavía al término municipal de Utrera-, junto a su fotografía (Fernández Casanova, inédito: tomo I, 59 y lám. 6) (fig. 7) donde se reconoce su colocación en el patio interior del citado castillo, y añade:

\section{“...efigie de león propiedad del Sr. Cuadra quien la trasladó a Utrera.” .}

Fue éste Enrique de la Cuadra y Cibaja, vecino de Utrera, quien en 1886 compró el castillo de Los Molares procediendo a su restauración (Moreno 1991: 183) y en el marco de aquellos trabajos en circunstancias que desconocemos incorporó la escultura cabeceña junto al otro fragmento leonino ya citado. Hacia la década de los años veinte de aquella centuria el entonces propietario, el Conde de la Maza, vendió la propiedad del castillo molarense, pero se llevó ambas piezas que, posteriormente, ingresan en el citado Museo ursaonense.

Si observamos la vieja fotografía que realizó Fernández Casanova (fig. 7) podríamos pensar que nos encontramos ante otro ejemplar similar a dos de los descritos de Las Cabezas de San Juan y de Lebrija y fruto de ese taller local antes citado, pero el análisis directo de la pieza ofrece evidentes sorpresas, fruto del alto grado de deterioro que presenta. La escultura ha sido elaborada en piedra arenisca (fig. 8), que tiene una enorme capa de pátina negruzca como fruto de su colocación a la intemperie durante mucho tiempo, a lo que apunta asimismo el profundo deterioro de toda la superficie y, sobre todo, de la parte superior del animal, que ha erosionado la cabeza, lomo y cuartos traseros. Asimismo se le ha recortado la zona inferior de las patas traseras -lo que le da ese aspecto especialmente agachado en la parte posterior-, quizás para facilitar su asiento (originariamente en Las Cabezas o bien ya en Los Molares), aunque se reconoce aún la representación de las costillas en ambos laterales y la cola que sale por debajo de la pata derecha y se enrolla en la parte derecha del costillar. Las dos patas las tiene extendidas hacia delante, pero la izquierda dispuesta en posición más elevada y colocada sobre un elemento asimismo bastante erosionado pero que corresponde a una típica cabeza de carnero. La cabeza del león se dispone girada hacia su derecha y aunque está también bastante deteriorada en su frente, reconociendo sólo la boca, conserva por su parte izquierda restos de la melena, mediante mechones dispuestos de forma naturalística (fig. 9).

El carácter naturalístico de la representación parece apuntar a una datación más reciente que la de los otros dos leones cabeceños anteriormente tratados, dentro de la consideración-que puede ser evidentemente discutible, pero que es la que se ha empleado hasta el momento de forma mayoritaria (Chapa Brunet 1985; Pérez López 1999)- de que en las formas más "evolucionadas", que remiten al mundo romano e itálico, se observaría un mayor naturalismo en la representación de las figuras y detalles formales como el giro de la cabeza o la presencia de la cabeza cortada bajo la zarpa. En concreto, la torsión de la cabeza de este león indica que se situaría decorando la parte superior de un monumento a dado ocupando la esquina izquierda.

No se ha documentado arqueológicamente ninguna de las necrópolis urbanas de la ciudad romana de Las Cabezas de San Juan. Descartada su identificación con Vgia hemos planteado la hipótesis de que pueda tratarse de Conobaria (Beltrán Fortes 1999), que aunque recibió la municipalidad en época flavia debió tener un importante desarrollo durante época republicana y, sobre todo, julio-claudia, si nos atenemos a su posición geográfica y topográfica -en el reborde del lacus Ligustinus, como asimismo ocurre con Nabrissa- 
y, especialmente, a los indicios que ofrece la descontextualizada documentación arqueológica y epigráfica con la que contamos. Así, el texto grabado en bronce de un ius iurandi pro salute Augusti et Domus Augustae, del 6-5 a.C., y el monumento epigráfico ya citado dedicado al emperador Claudio en el 48 d.C. (González Fernández 1996: 345ss.), o restos de monumentales esculturas marmóreas que debieron de formar parte de un programa imperial de época seguramente julio-claudia (Beltrán Fortes e.p.). También han ido recuperándose de forma casual otros elementos que muestran ese proceso de "monumentalización" de la arquitectura funeraria típico de necrópolis urbanas surpeninsulares sobre todo desde época de Augusto en adelante (por ejemplo, Beltrán Fortes 1990 y 1997; Hesberg 1993; Beltrán Fortes y Baena del Alcázar 1996), que se vincula a la adopción de formas itálicas, como los mausoleos turriformes-cerrados o con edículas en las que se exponían las estatuas funerarias-o los de forma a dado, que se coronaban con pulvinos -imitando un altar monumental- o con figuras de leones.

De la necrópolis oriental ${ }^{9}$ de la ciudad romana de Las Cabezas de San Juan, que debió ser quizás la más importante, en relación con la salida que conectaba con la cercana via Augusta, se han recuperado dos estatuas funerarias sedentes de matronas, de arenisca que luego iría estucada, de las que se ha dicho que “...ambas proceden del mismo taller, seguramente del mismo escultor y podrían ser fechadas en torno al tercer cuarto del siglo I a.C." (León Alonso 1990: 370, lám. 42, b). De procedencia exacta desconocida dentro del yacimiento arqueológico de Las Cabezas conocemos también un pulvino de grandes dimensiones, elaborado en arenisca y datable en el siglo I d.C., que coronó un mausoleo en forma de altar (Beltrán Fortes e.p.).

En relación a lo indicado antes de la influencia directa del mundo romano-itálico en estas manifestaciones escultóricas de los territorios del Bajo Guadalquivir, es plausible que estos leones funerarios ocuparan de forma habitual una posición similar a la documentada de forma mayoritaria en territorio itálico -como en la conocida tumba pompeyana de los Stronii-, es decir, ocupando la parte superior de las dos esquinas frontales del monumento funerario, generalmente de forma a dado, tal como, tomando como ejemplo una tumba de opus quadratum de la necrópolis de Gades, mantiene Pérez López (1999: 28ss., figs. 18 y 20) ${ }^{10}$ (fig. 9)-, lo que explica la torsión de la cabeza del animal hacia uno de los lados, según la posición original que ocupara en el coronamiento de la tumba. Si esa torsión más o menos acentuada se advierte en dos de los leones cabeceños, por el contrario en uno de ellos -el conservado actualmente en la Colección Arqueológica Municipal- no se documenta, por lo que asimismo podría pensarse en la colocación sobre pedestales en el entorno de la tumba correspondiente sobre la que ejercería su función apotropaica.

9. De esta zona se ha dicho que debe proceder el león casi completo conservado ahora en la colección municipal, de un lugar contiguo a un enorme solar llamado "cerro Mariana” (López García 1999: 243). Hemos llevado a cabo excavaciones arqueológicas de urgencia en la parte alta de este solar-que corresponde a un área intramuros-pero debido a un arrasamiento producido hace varios decenios de la parte superior de los depósitos arqueológicos sólo se documenta una secuencia de ocupación desde época orientalizante (ss. VII-VI a.C.) a turdetana (s. IV a.C.), según Beltrán Fortes y Escacena Carrasco (2001).

10. Sin negar, pues, la tesis general, nos parece que no puede mantenerse esa hipótesis concreta para el caso de esta tumba ya que, por un lado, es evidente que no pueden unirse los restos conservados de la inscripción monumental tal como se propone en el montaje museístico y en el dibujo y, por otro lado, los elementos que faltan al epígrafe funerario -que sólo presenta un cognomen femenino y otro masculino de un séviro augustal- y el tamaño de las letras abogan por un frente arquitectónico de mayores dimensiones. El epígrafe se recoge ya en López de la Orden y Ruiz Castellanos (1995: $\mathrm{n}^{\circ}$ 139). Para el modelo de colocación de esculturas zoomorfas exentas en el mundo ibérico como coronamientos de pilares-estela vid., por ejemplo, Almagro-Gorbea (1983). 
JOSÉ BELTRÁN FORTES

\section{BIBLIOGRAFÍA}

ALMAGRO-GORBEA, M. (1983): "Pilares-estela ibéricos”, Homenaje al Prof. Martín Almagro Basch. III. Madrid, Ministerio de Cultura: 7-20.

BAENA DEL ALCÁZAR, L. (1995): “A propósito de uno de los athloi de Hércules: las representaciones de Atlas en la Mauretania y en la Bética", Actas del II Congreso Internacional sobre El Estrecho de Gibraltar. Madrid, UNED: tomo II, 347-352.

BELTRÁN FORTES, J. (1990): "Mausoleos romanos en forma de altar del sur de la Península Ibérica", AEspA 63: 183-226.

(1999): "Las Cabezas de San Juan (Sevilla): de Vgia a Conobaria", Habis 30: 283-295.

_- (1997): "Monumentos funerarios", Hispania Romana. Desde tierra de conquista a provincia del Imperio. Milán-Madrid, edt. Electa: 119-125.

— (en prensa): "La ciudad romana de Conobaria", Ayuntamiento de Las Cabezas.

BELTRÁNFORTES, J. y BAENA DEL ALCÁZAR, L. (1996): Arquitectura funeraria romana de la colonia Salaria (Úbeda, Jaén). Ensayo de sistematización de los monumenta funerarios altoimperiales del Alto Guadalquivir. Sevilla, Junta de Andalucía.

BELTRÁNFORTES, J. y ESCACENA CARRASCO, J.L. (2001): "Excavación y seguimiento arqueológicos en el cerro Mariana, en el casco urbano de Las Cabezas de San Juan (Sevilla)", Anuario Arqueológico de Andalucía 1998. III, vol. II: 1014-1021, Sevilla.

BLANCO FREIJEIRO, A. (1981): Historia del Arte Hispánico. I. La Antigüedad. 2. Madrid, edt. Alhambra.

BRUNA Y AHUMADA, F. de (1773): "Noticia, y explicación de un monumento antiguo romano, descubierto en la Villa de Las Cabezas de San Juan, del Arzobispado de Sevilla", Memorias Literarias de la Real Academia Sevillana de Buenas Letras. Tomo primero. Sevilla.

- (1790): Reflexiones sobre una lápida gótica encontrada a una legua de la villa de Utrera, con cuyo motivo se habla del Obispado Asidonense, Real Academia de la Historia de Madrid, Mss. 9/3940 (19).

CARO, R. (1634): Antigüedades y Principado de la Ilustrissima Ciudad de Sevilla y Chorographia de su Convento Iuridico, o Antigua Chancillería. Sevilla, Impr. Andrés Grande.

CHAPA BRUNET, T. (1985): La escultura ibérica zoomorfa. Madrid, Ministerio de Cultura.

FERNÁNDEZ CASANOVA, A. (inédito): Catálogo Monumental de España. Provincia de Sevilla. Madrid, Ministerio de Instrucción Pública y de Bellas Artes.

HESBERG, H. von (1993): "Römische Grabbauten in den hispanischen Provinzen", Hispania Antiqua. Denkmäler der Römerzeit. Mainz, Philipp von Zabern: 150-181.

JIMÉNEZ, A. (1999): "Oficio de mirones", El espíritu de las antiguas fábricas. Escritos de Adolfo Fernández Casanova sobre la Catedral de Sevilla (1888-1901). Sevilla, FIDAS, Serie Investigación, nº 4: 11-33.

LACALLE RODRÍGUEZ, R. (1998) [1999]: "Ensayo de definición arqueológica de las etnias prerromanas de Andalucía”, Spal 6: 165-186.

LEÓN ALONSO, P. (1990): "Ornamentación escultórica y monumentalización en las ciudades de la Bética", Stadtbild und Ideologie. Die Monumentalisierung hispanischer Städte zwischen Republik und Kaiserzeit. München, Bayerische Akademie der Wissenschaften: 367-380.

LÓPEZ DE LA ORDEN, D. y RUIZ CASTELLANOS, A. (1995): Nuevas inscripciones latinas del Museo de Cádiz, Cádiz, Universidad.

LÓPEZ GARCÍA, I. (1999): “Una escultura de león. Las Cabezas de San Juan (Sevilla)”, Baetica 21: 239-248. MORENO CURADO, A. (1991): Villa de Los Molares. Pasado y presente. Los Molares, Ayuntamiento. PÉREZ LÓPEZ, I. (1999): Leones romanos en Hispania. Madrid, Fundación de Estudios Romanos y Fundación Focus-Abengoa. 
ROMERO MURUBE, J. (1965): Francisco de Bruna y Ahumada. Sevilla, Ayuntamiento.

SILLIÈRES, P. (1976): "La Via Augusta de Cordoue à Cádiz. Documents du XVIII siècle et photographies aériennes pour un étude de topographie historique", $M C V$ 12: 27-65.

TOMASSETTI GUERRA, J.M. (1997) [1999]: "Contribución al estudio del urbanismo antiguo en el Bajo Guadalquivir: el caso de Lebrija (Sevilla)”, Spal 6: 243-262. 


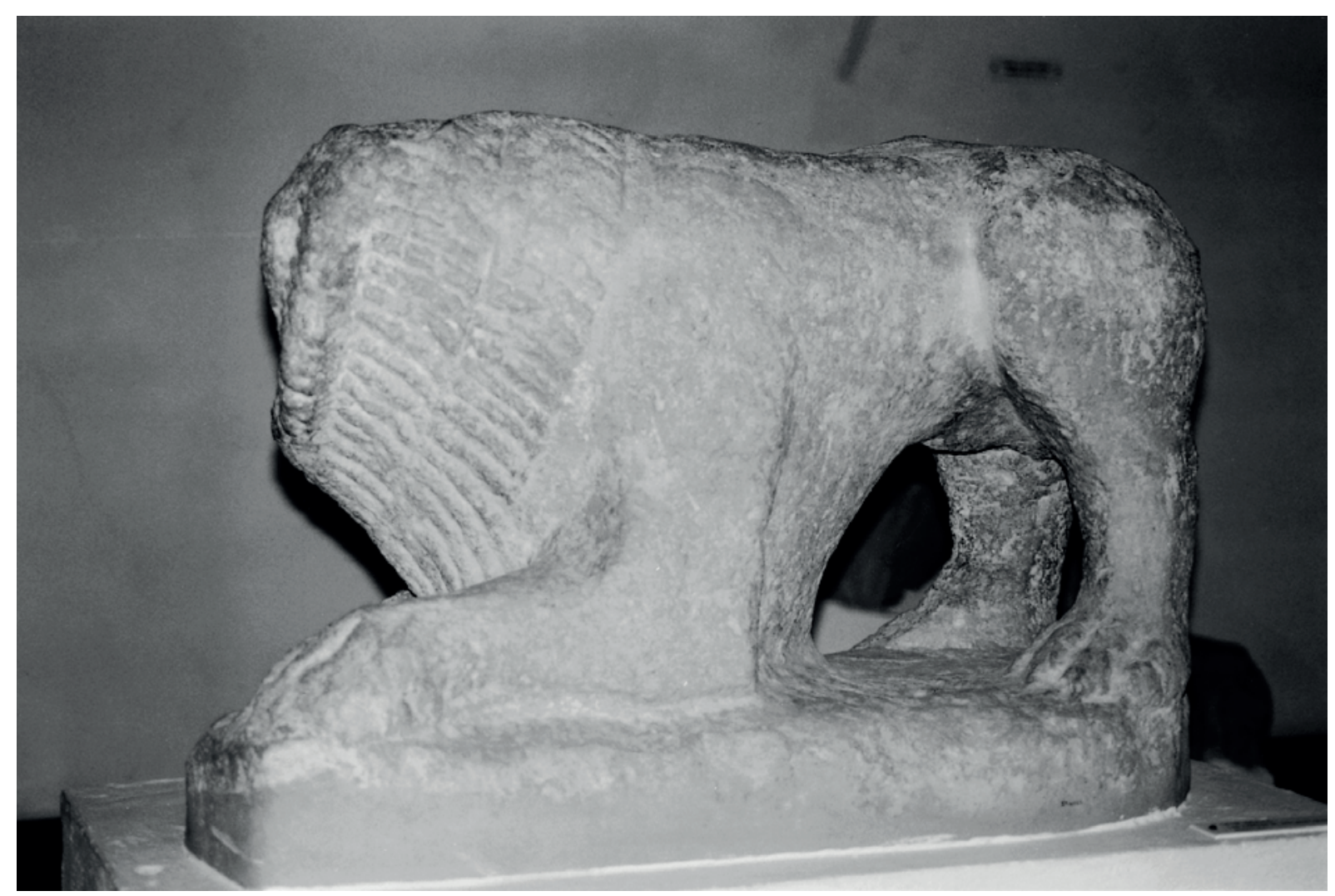

Fig. 1. León funerario de Las Cabezas de San Juan (Sevilla). Museo Arqueológico Provincial de Sevilla, Sala XI (nº inv. 647). 


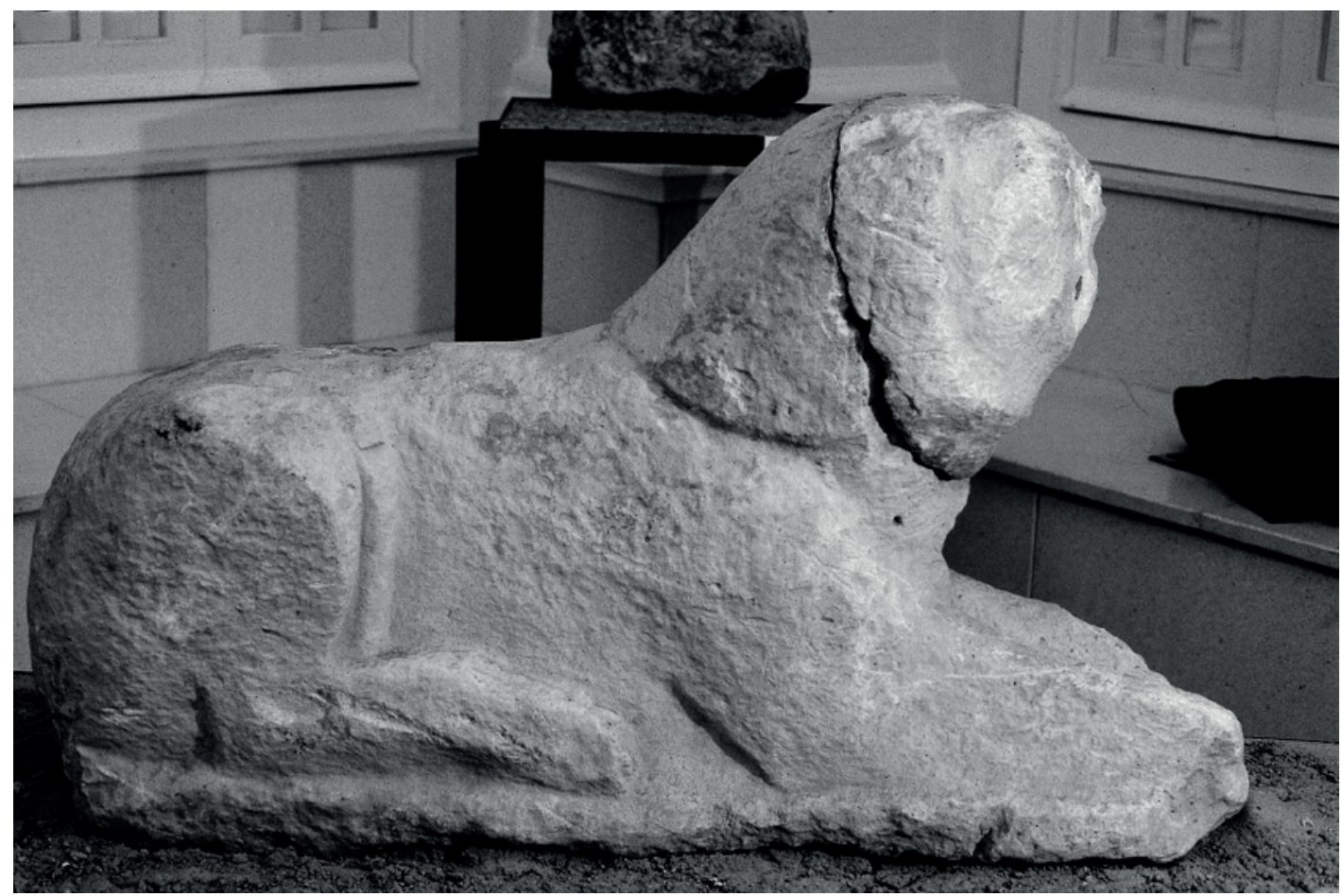

Fig. 2. León funerario de Las Cabezas de San Juan (Sevilla). Colección Municipal.

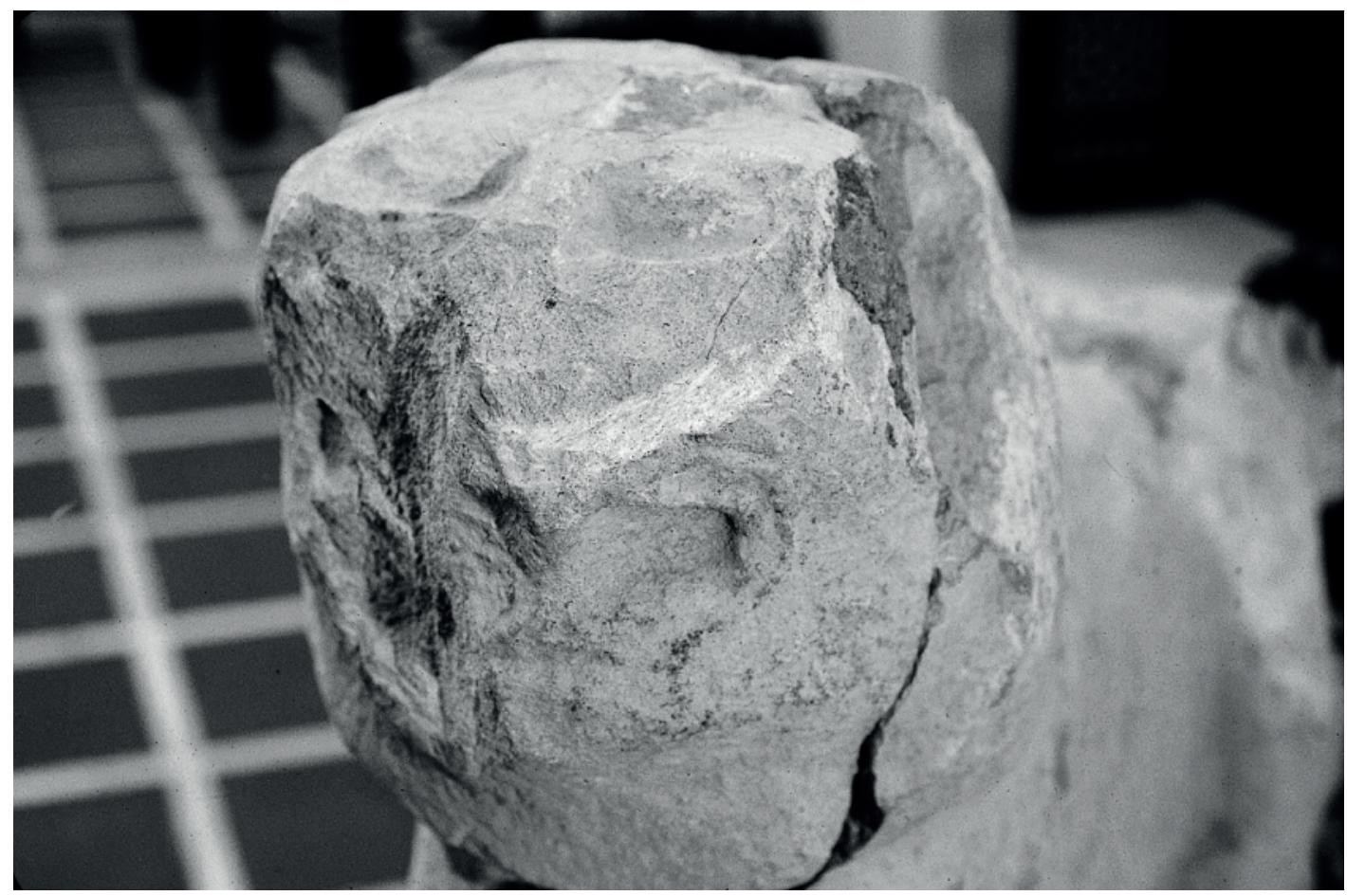

Fig. 3. Ídem. Detalle de la cabeza.

ISSN: 1133-4525 ISSN-e: 2255-3924 


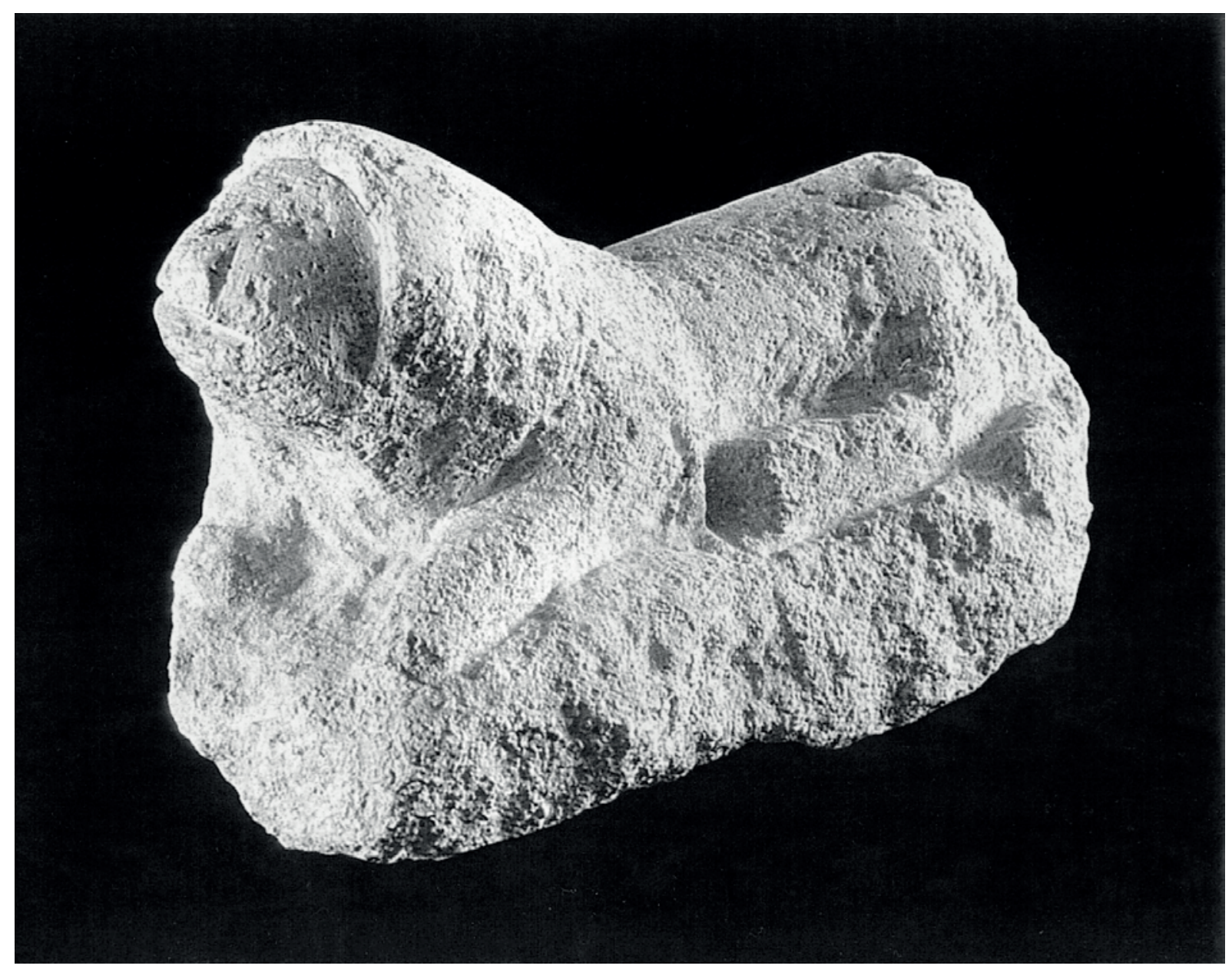

Fig. 4. León funerario de Lebrija (Sevilla). Colección particular. Según Pérez López (1999: 79). 


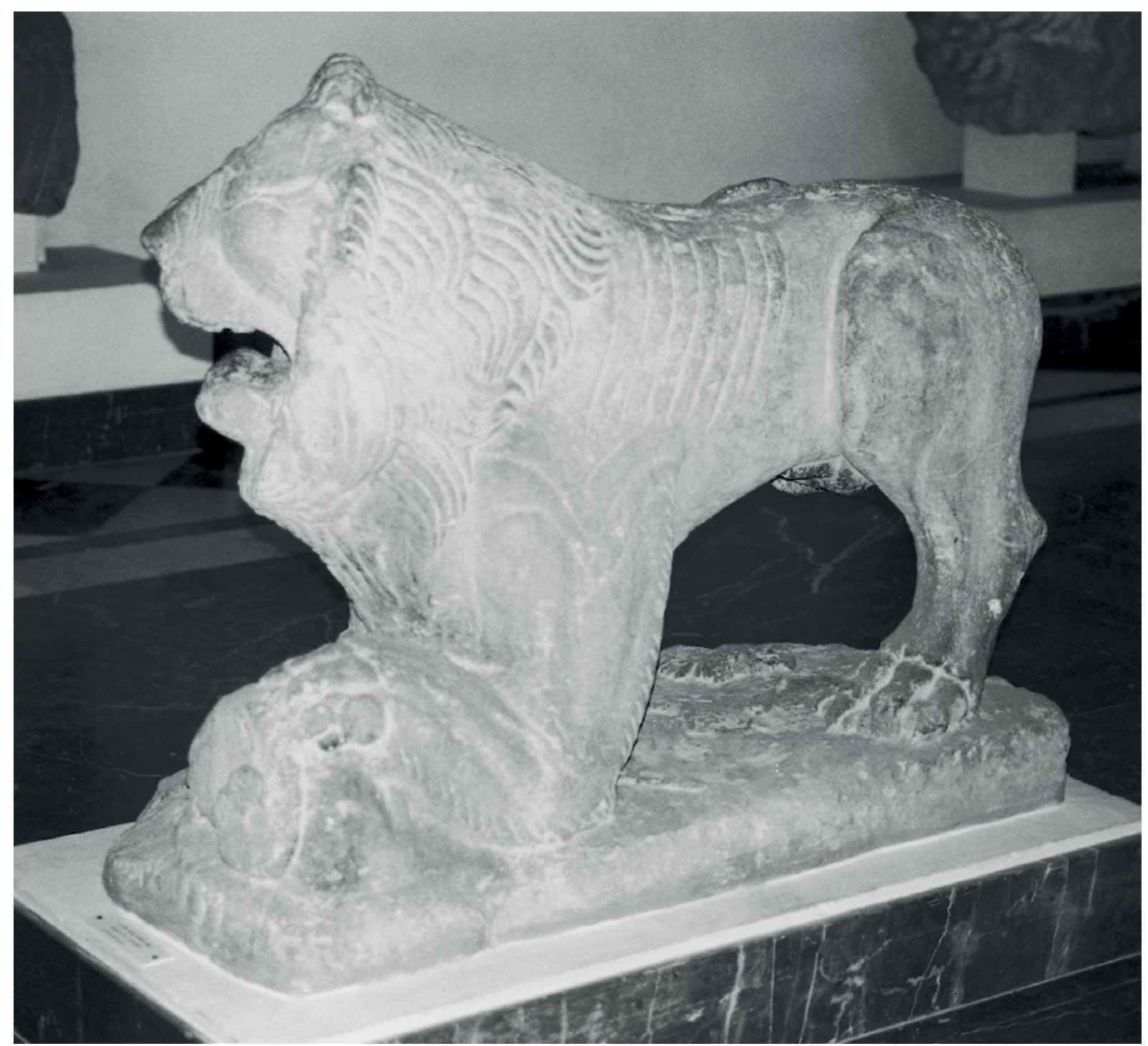

Fig. 5. León funerario de Lebrija (Sevilla). Museo Arqueológico Provincial de Sevilla, Sala XI (nº inv. 6980). 


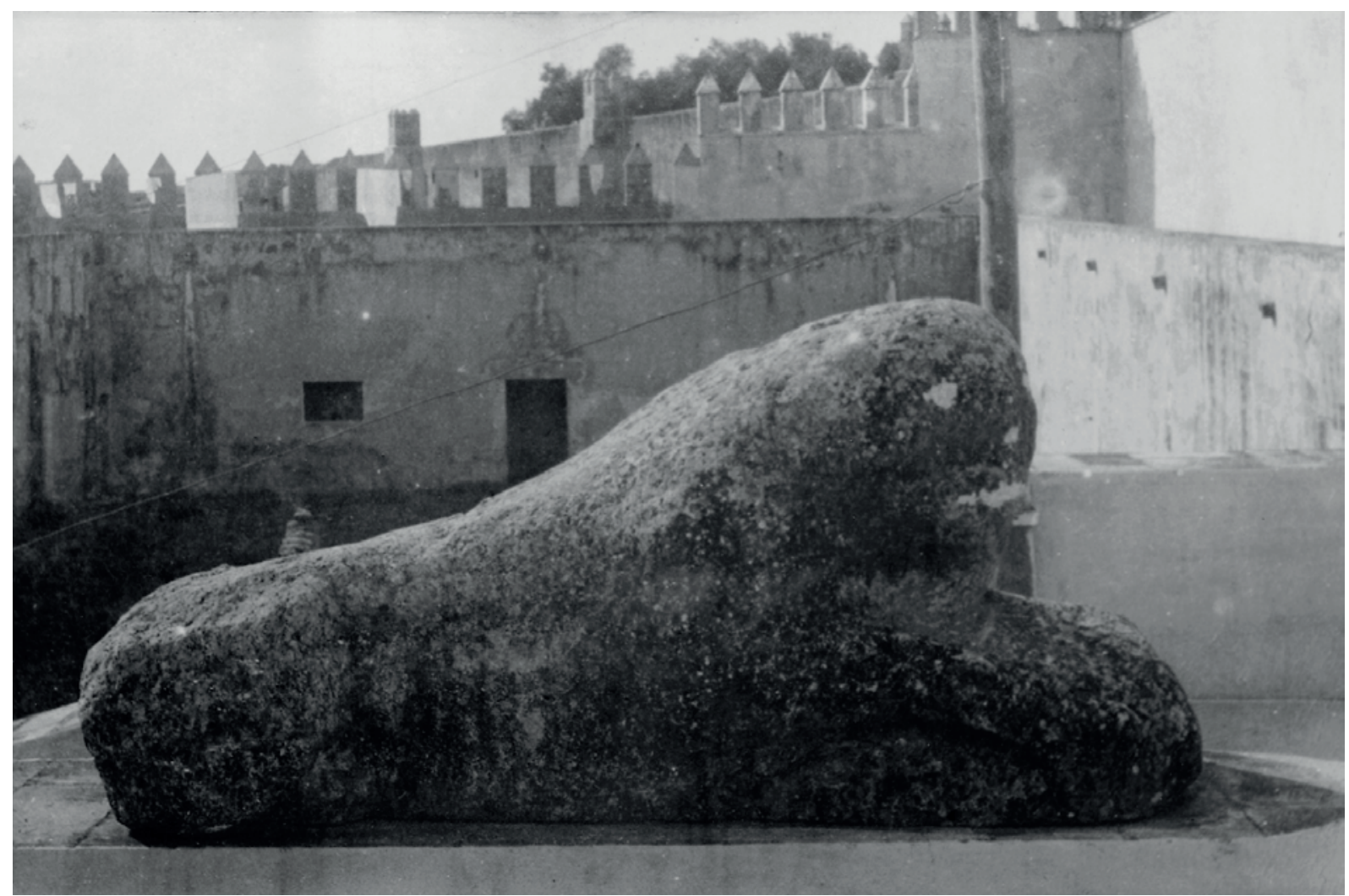

Fig. 6. León funerario de Las Cabezas de San Juan (Sevilla) en su ubicación en el patio del castillo de Los Morales, a principios del siglo XX, según fotografía de Fernández Casanova (1907-1909: inédito, lám. 6). 


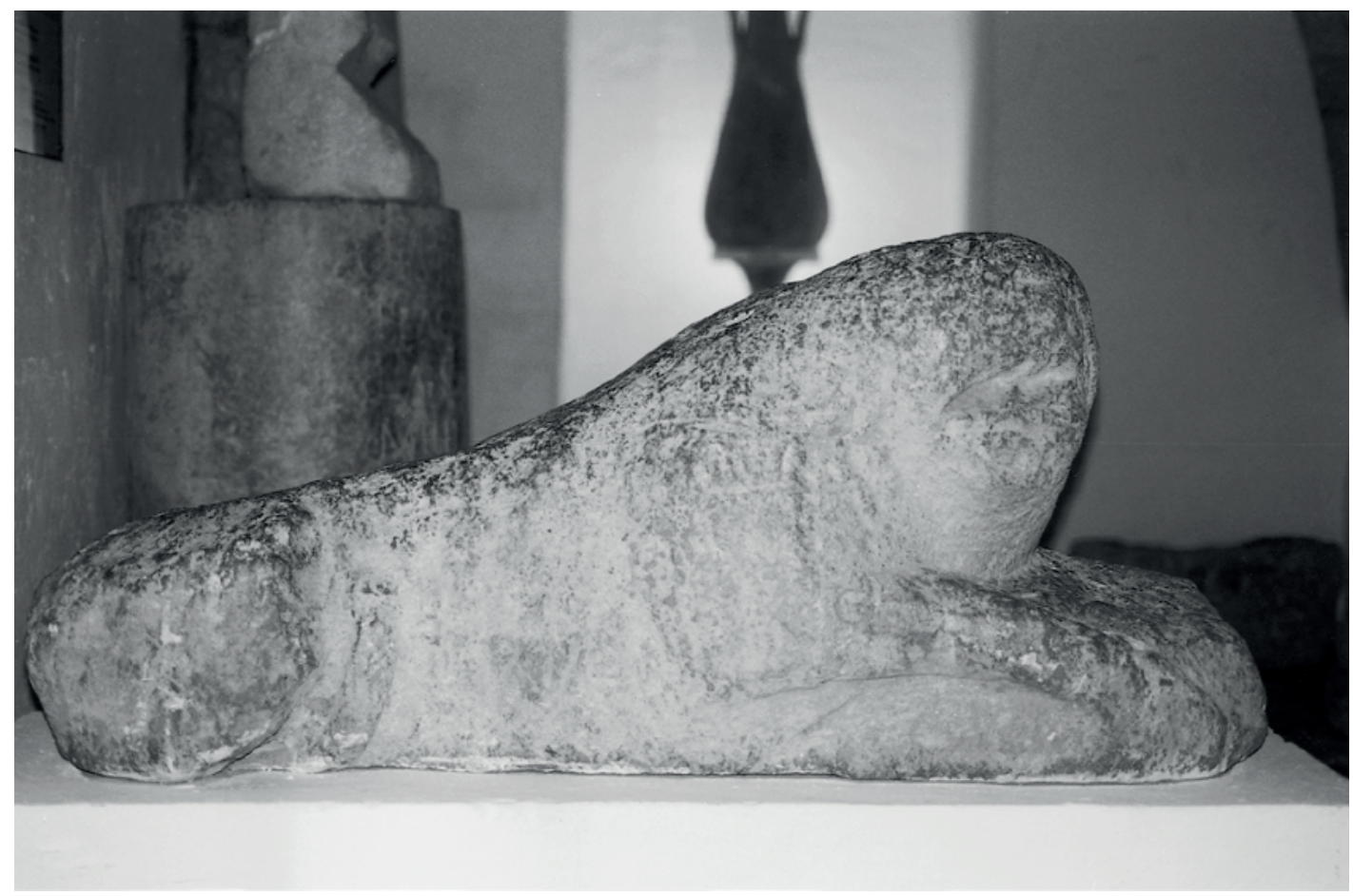

Fig. 7.Ídem, en su localización actual, en la Sala II del Museo Arqueológico Municipal de Osuna.

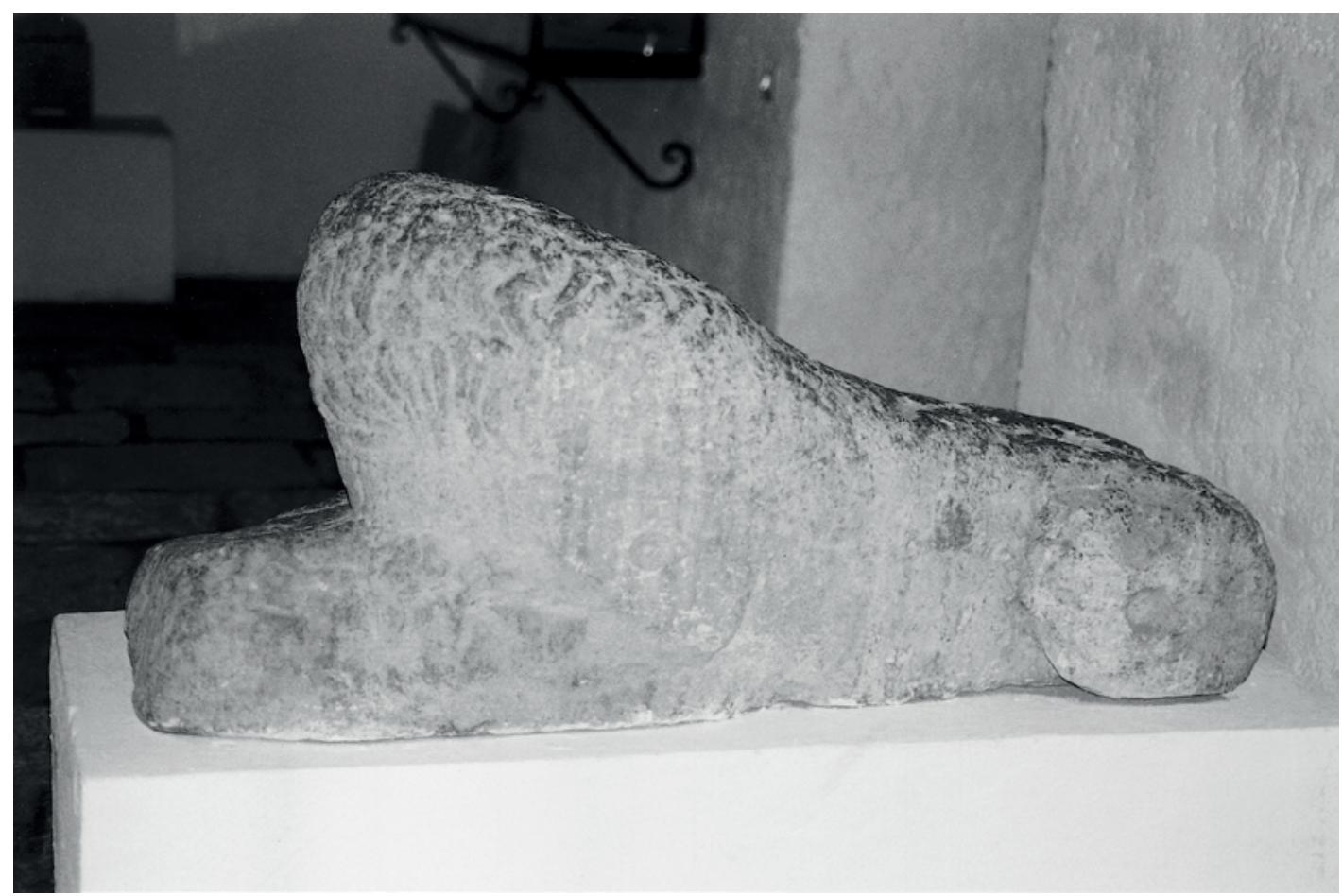

Fig. 8. Ídem. Lateral izquierdo.

ISSN: 1133-4525 ISSN-e: 2255-3924

http://dx.doi.org/10.12795/spal.2000.i9.24 


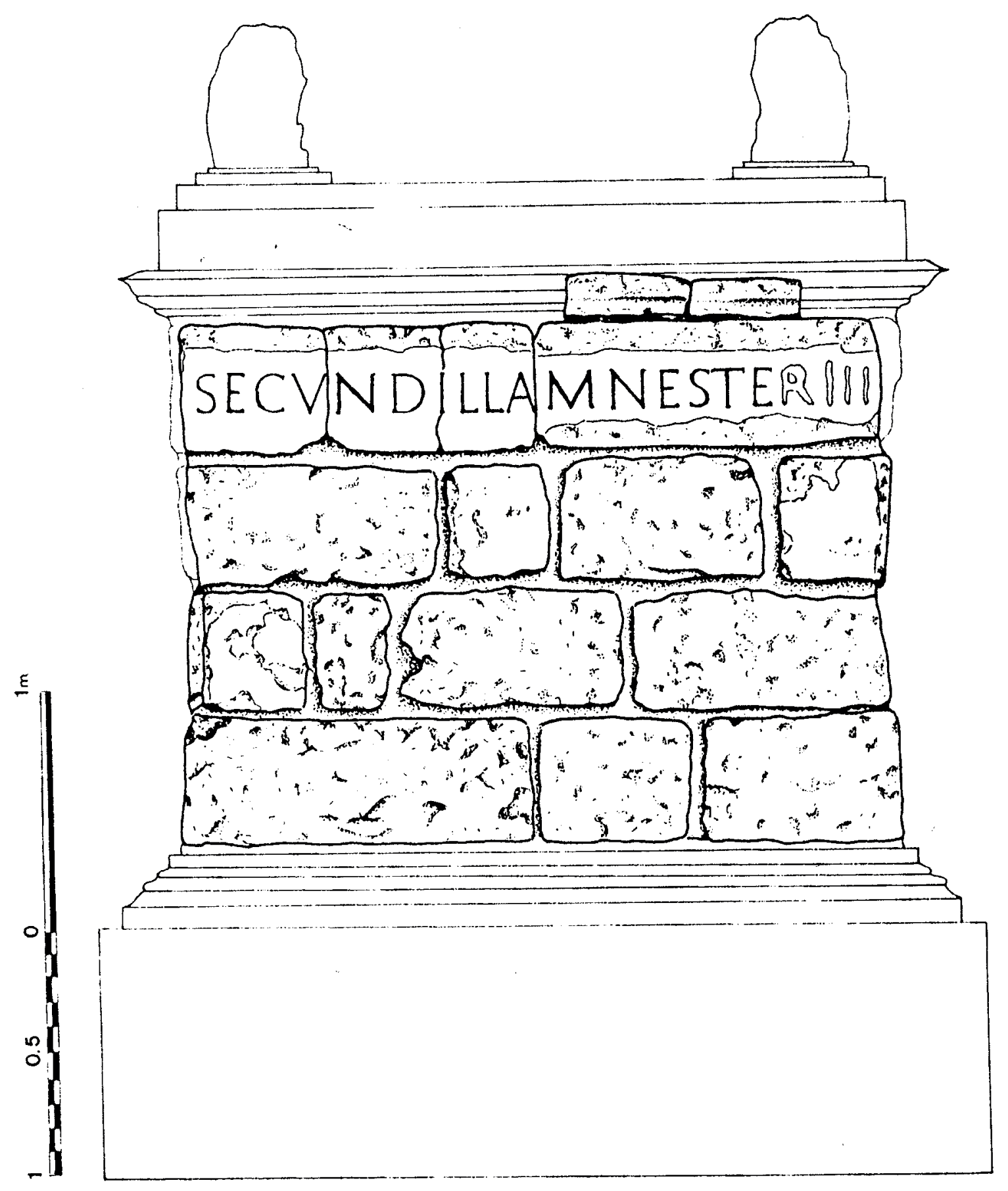

Fig. 9. Reconstrucción ideal de una tumba romana de Gades (Cádiz) coronada por dos leones. Según Pérez López (1999: Fig. 18) 